\title{
Social capital across the life course: Accumulation, diminution, or segregation?
}

\author{
Beate Volker ${ }^{1 *}$ (i) \\ Department of Human Geography and Spatial Planning, Utrecht University \\ *Corresponding author. Email: b.volker@uu.nl \\ Special Issue Editors: Brea L. Perry, Bernice A. Pescosolido, Mario L. Small, and Ann McCranie
}

\begin{abstract}
This study examines changes in individual social capital during adult life within a 19-year period. Social capital theory and life course theory are combined, and it is argued that changes in social networks do not necessarily go together with changes in social capital: while personal networks are known to decline in size with age, social capital can be expected to accumulate, in particular for those who had a better starting position and therefore more resources to share. Panel data from the survey of the social networks of the Dutch (SSND) (1999-2018) at four points of measurement are employed to inquire into this argument. Social capital is measured by the position generator instrument, and three indicators, that is, resource extensity, mean prestige access, and resource range are analyzed. Results of fixed effect models show that, on average, people maintain access to social capital, and that men and higher educated gain social capital through their life as opposed to women and lower educated. Implications for the understanding of the reproduction of social inequality are discussed. The paper concludes with a reflection upon the value of ego-centered network analysis in the era of big data and data science.
\end{abstract}

Keywords: social capital change, life course and social capital

\section{Introduction}

Since the 1970s, research on social capital is flourishing. The basic principle of social capital theory comprises the idea that networks and their structures have a meaning-they influence an individual's possibilities to achieve important goals in life. Relationships do not come out of the blue but are actively build and individuals benefit from the resources embedded therein. Resources that can be mobilized via social relationships constitute what is referred to as social capital (see Flap \& Volker, 2013). Social capital fundamentally differs from other types of resources, such as financial capital or human capital, in particular concerning its property rights (Coleman, 1988) and its variety in discount rates (cf Glaeser, 2001). In particular, Bourdieu (1981) made a distinction between different forms of capital and argued that social capital can function as a multiplier to other forms of capital.

In the early years of social capital research, most studies were directed to the question of how people get their job (with Granovetter, 1973, as the first seminal paper, followed by many others, e.g., Lin, Ensel \& Vaughn, 1981; De Graaf \& Flap, 1988; Flap \& Boxman, 2001; Mouw, 2003; Chen $\&$ Volker, 2016). More recently, inquiries into the returns of social capital have been undertaken in almost every domain of life (see Halpern, 2005, for an overview). For example, social capital and its consequences have been examined with regard to living longer, staying healthy (Kawachi, 1999; Kawachi, Kennedy \& Glass, 1999; Mohnen et al., 2011), getting a house (Röper, Volker \& Flap,

(C) The Author(s), 2020. Published by Cambridge University Press. This is an Open Access article, distributed under the terms of the Creative Commons Attribution-NonCommercial licence (http://creativecommons.org/licenses/by-nc/4.0/), which permits non-commercial re-use, distribution, and reproduction in any medium, provided the original work is properly cited. The written permission of Cambridge University Press must be obtained for commercial re-use. 
2009), a car (DiMaggio \& Louch, 1998), performing on the job (Thompson, 2005, Flap, Bulder \& Volker, 1998), managerial performance (Burt, 1992; Moran, 2005) as well as performance of organizations (Leana \& Pil, 2006), governments (Boix \& Posner, 1998), and states (Putnam, 1993; Son, 2012).

The fact that social capital helps to attain important goals in life, or even more, that it helps to attain the commodities necessary to build a life, stay healthy, and attain better "life chances" (cf Max Weber) in general, poses a criticism to the meritocratic ideal of modern society. Social capital research has convincingly shown that in all important areas of people's life, universalist rules are not the only-and often not even the most important-rules that matter. One accomplishes an important goal not only because of own merits but (also) because of who one knows, or by whom one is known. Therefore, social capital is key to an understanding of society and the issues related to social inequality and cohesion.

Although the significance of social capital is established in a host of studies, knowledge about how social capital is created and changes through time and across individual lives is comparably scarce. Interestingly, changes in networks when people grow older as well as network changes across the life course or after critical life events are much better documented than changes in social capital (see Gottlieb \& Green, 1984; Kalmijn, 2012; Schulz \& Tompkins, 1990; Wrzus et al., 2013). However, a change in a network is not inevitably a change in social capital and vice versa. It is one of the interesting implications of the theory of social capital that people can have a vital network but nevertheless no or just very little social capital for attaining a better life. For example, studies of criminal peers (Volker et al., 2016), battered wives (Rusbult \& Martz, 1995), or of unemployed (Nordenmark, 1999) demonstrate that people can lack social capital but nevertheless have many social network ties.

This paper aims to contribute to the knowledge on changes in social capital across the life course within a 19-year period using a representative sample of respondents in the Netherlands. It combines arguments from social capital theory with arguments from life course theory and examines hypotheses with panel data information on people's social resources. The research question is straightforward: How does social capital in people's networks change through their lifetime and can we understand these changes by arguments from life course and social capital theory?

In what follows, I first review existing empirical knowledge on social capital changes across people's life, discuss the principles of social capital theory, combine them with life course theory, and formulate general expectations on changes in social capital. Next, the position generator instrument as a measurement of ego-centered social capital is described. The remaining sections address data and other measurements, results, and conclusion, respectively.

\section{State of the art: Changes of social capital through people's life}

If one agrees that social capital is a crucial resource, the question of how and why social capital changes in someone's life becomes important. For an individual, it might be worthwhile to understand in what period of life social capital shortages might occur-and what can be done against it. More general, knowledge about lifetime changes in social capital might help to provide advice to policymakers regarding the timing of policies directed to social capital creation, and regarding who will benefit from such policies. For example, creating opportunities for people to enlarge their social capital might be sensible in particular life stages of particular groups but less so in others. Last but not least, knowledge about changes in social capital across the life course can bring important nuances to what already is known about network changes. As already mentioned, a decline in network size, as shown by studies on networks through the life cycle (Fischer \& Oliker, 1983; Kalmijn, 2012; Wrzus et al., 2013), does not imply a decline in social capital. Importantly, if people do not miss important social resources in their lives when they grow older, the decline of network size among the elderly will change its interpretation. On the other hand, younger people-known to have comparatively large networks-might actually lack social 
resources embedded in ties to other people. In a nutshell, a better understanding of the interplay between networks and resources across the life course might help to better understand network effects as well as mental health issues such as loneliness and depression.

\subsection{Life course}

Research on social capital changes across people's life course is relatively scanty. McDonald \& Mair (2010) are among the few, who explicitly focused on life course changes in social capital. Results, based on a cross-sectional, representative sample of adults in the US between 22 and 65 years of age, show that, while there is a general decline in contact frequency and sociability with age, occupational-based social capital is larger among older people but eventually levels off among those who are retired. Furthermore, the authors found that patterns between men and women differ, probably due to their differences in life course trajectories and social positions: younger women have less occupational-based social capital than younger men, but this gap seems to be closed among older women and men (see also Erickson, 2004).

\subsection{Selected social groups, critical life events, and specific types of relationships}

Other studies do not consider social capital explicitly but examine social connectedness and embeddedness of different social groups or in relation to a specific life event, such as migration or divorce. For example, Cornwell, Laumann, and Schumm (2008) showed for a cross-sectional sample of people between 57 and 85 years of age that the common association between older age and increased loneliness does not hold for everyone, since many elderly have rich and vital networks (see also Cannuscio, Block \& Kawachi, 2003). While negatively related to network size, age is found being positively related to socializing with neighbors, religious participation, and volunteering, which suggests that older adults often have many social resources. In similar vein, Cornwell (2011) studied what he called "bridging potential" in networks of older men and women, understood as the number of alter pairs in a network, who are not connected to each other. While age in general is assumed to be negatively related with bridging, Cornwell found that elderly women were more likely than men to have these potential bridges in their network, running usually between kin and non-kin contacts. In line with this, gender differences have been found to increase with age: women at a higher age have a network that is richer and with more resources than men.

A study focusing specifically on the younger generation is done by Weller (2010). She argued that young people-more than older ones-are active in creating social capital, in particular beyond the family. According to her, the dynamic nature of social capital and its importance for identity formation at younger age is actually underestimated and understudied.

Hagan, MacMillan \& Wheaton (1996) studied changes in social capital after migration. Using arguments from life course perspectives (Elder, 1994, see below), they found that negative effects of migration, that is, loss of community, can be mitigated by other ties such as ties to parents and through parental involvement. More theoretically, O'Rand (2001), while speaking of "life course capital," argues that social (and human) capital links patterns of inequality between individuals and cohorts with life course outcomes.

Furthermore, while not studying social capital explicitly, Kalmijn (2012, see also Kalmijn, 2003) found changes in social networks after important transitions and life events that imply also changes in social capital. Using large-scale panel data (the Swiss Household Panel) over a 12-year period, he found that marriage did not affect the number of weaker ties, but most changes occurred among the stronger ties to friends: they become less important and smaller in number. Furthermore, parenthood goes together with a shift to more local ties. Last but not least, for women, divorce and widowhood have positive effects on the number of contacts and support received from their personal network. In similar vein, Wrzus et al. (2013) established in a metaanalysis of 277 studies that after adulthood one's network decreases steadily in size and that, next 
to this, specific life events affect decrease or increase of networks, such as parenthood (decrease) or entering the job market (increase). With regard to parenthood, Song (2012) found that this life event affects social capital of men and women differently: parenthood has positive effects on men's social capital, but it seems to weaken social capital of women and unmarried.

Last but not least, David-Barrett et al. (2016) study variation in close contacts at different stages in life and find that the changes in dependency and reliance are mirrored by communication patterns: while during young adulthood the shift is made from family communication to friends, at older age people depend more on their children and friends are less important in their communication patterns. The authors suggest that such life stage patterns in social relationships are universal.

\subsection{Different social contexts}

A number of studies on social capital changes are directed to contexts, mostly the contexts of health and crime. With regard to studies on health, in particular, the work of Song \& Lin (2009, see also Song, 2011) is a good example. They established a clear effect of social capital on overall perceived health as well as on depressive symptoms, next to the effect of social support.

Regarding studies on crime, Sampson and Laub (1990, see also Laub, 2006) investigated the protective nature of social bonds with longitudinal data and demonstrated that, while early criminal behavior predicts becoming an offender in later life, strong social relationships such as a marriage - as an indicator for social resources-dampens the likelihood of deviant behavior.

Finally, it is noteworthy that differences in social capital as a consequence of particular surrounding institutional patterns or social environment/opportunities have been studied. Interesting findings have been established concerning differences between individualistic societies (such as the US) and collectivist societies (such as China and Taiwan), see McDonald, Chen \& Mair (2015), Volker (1995), and for natives as opposed to migrants in the Netherlands (Volker, Pinkster \& Flap, 2008).

\subsection{Taking stock}

In summary, a number of studies examined changes in social networks across the life course after critical events, in specific settings, or for specific social groups. Very few studies explicitly inquired into social capital changes, and, importantly, all studies are cross-sectional. In addition, indicators for network change, social capital change, or sociability are inconsistent and not always based on theoretical assumptions which make findings hard to compare. All in all, it seems that while patterns of network changes are-by and large-well established, social capital patterns are much less clear. Consequently, there is not much knowledge on social capital changes across people's life.

\section{Social capital theory}

When theorizing about social capital, it is important to distinguish between three dimensions: i) first, the micro level as opposed to the macro level, ii) second, actual as opposed to hypothetical mobilization of resources, and iii) third, access as opposed to use of social capital.

Ad i) Micro-level social capital consists of the resources embedded in people's networks and relationships, while macro-level social capital refers to the resources of a community. Studies on returns of social capital for individuals are usually on the micro level. At the core of microlevel social capital (see Lin, 1999, Lin, Fu \& Hsung, 2001; Bourdieu, 1981)-quite popular in sociology-are two propositions: first, people, who have more social resources are better able to achieve all goals in life than people with fewer resources. Second, it is the investment in relations to others that creates social capital (e.g., Flap \& Volker, 2004, 2013). When people do a favor for 
someone, they create social capital (Coleman, 1990:306, used the term "credit slips" to indicate that people are indebted to those who helped them before). The theory assumes that people invest in others having future benefits in mind (see Axelrod, 1984, on the "shadow of the future"). ${ }^{1}$

On the other hand, macro-level social capital theory (see Putnam, 2000, Coleman, 1990) proposes that social capital is provided via shared norms and values and that it facilitates cooperation, participation, and the production of collective goods (see Moore, Hawe \& Shiel, 2006). In this sense, macro-level social capital is a complement to economic markets in their allocation and distribution function. One can dispose of these resources because of being a member in a community - it is not required that one has many ties or a network. Importantly, macro-level social capital is not a result of individual investment but rather of membership and belonging. This makes this type of capital susceptible to free-riding behavior. As Coleman (1988) argued, collective good problems apply to social capital, because the individual who invests is not necessarily the same individual who will benefit.

Notably, studies on community or organizational functioning often employ macro-level social capital. While macro-level social capital is typically discussed together with issues related to social cohesion, micro-level social capital is more related to social inequality and is considered beneficial for the individual and not per se for the functioning of society as such. Both aspects of the theory meet, however, in their proposition that social capital facilitates the achievement of goals and the production of goods, which can be individual or collective, but cannot be achieved alone.

Ad ii), the dimension of actual as opposed to hypothetical social capital points at the difference between what people really have at their disposal and what they assume or expect to have-given a specific problem situation. For example, asking someone for help with repairing a bike and getting this help represents someone's actual social capital. Making a list of people one could possibly ask for help in case one's bike is broken refers to hypothetical social capital. Hypothetical social capital can be cognitively biased-assumed helpers might refuse to provide support when it is needed; they might not be able or willing to help. On the other hand, actual social capital depends solely on the problem situation at hand. If there is no bike to be fixed, the social resources that help in case a bike is broken are invisible. Both dimensions, hypothetical and actual, are important. Researchers want to understand to whom people turn for help in a situation of need and who finally helps, therefore they inquire into actual social capital. However, ones' cognitive suppositions on who one would turn in such cases probably impacts the risks people take in life and can therefore be expected to guide all kind of actions.

Ad iii), and finally, the dimension of access as opposed to use of social capital (Lin \& Erickson, 2008, Van der Gaag, 2004): one can have access to others with many resources, but this does not imply that the resources are also used in the end. For example, a family member who is a lawyer, provides access to the legal world, but if one needs legal advice, there are many conceivable reasons why one might not turn to that family member but to an unrelated professional. This dimension is related to, but not the same as the difference between actual and hypothetical social capital mentioned under ii). Access differs from use, because the owner of the resource accessed has to agree before it can be used. Also, people might refrain from using a resource even if it can be easily accessed and of which the owner is willing to help, for example, because they want to avoid becoming indebted. A resource that is accessed is not necessarily used, but a resource used can be accessed by definition. Further, actual use of a resource depends on a specific need or problem situation of an actor-and certain kinds of help might never be used because this situation does not occur.

\section{Social capital theory and life course theory combined}

This contribution examines actual, accessed micro-level social capital, using the position generator instrument, as described below. The theory of social capital provides at least three arguments 
about changes through time and across the life course. First, social capital declines if people stop investing in each other. Second, social capital changes, if it has no function anymore. "Social capital is defined by its function" (Coleman, 1988: S98). Third, there is a discount rate to social capital (see Glaeser, 2001, Glaeser, Laibson \& Sacerdote, 2002). Social capital loses its value if it is not renewed ${ }^{2}$. While these arguments explain that social capital can change (and vanish) during an individual's life, it is important to note that social capital is unequally distributed in a population. Those who control more economic, symbolic, and political resources, also have more social capital (see Lin, 2000, see also Lin, Ao and Song, 2008). Inequality in social capital can be understood by combining arguments from life course theory with social capital theory arguments. More in detail, life course theory complements the arguments from social capital theory, in particular through the notions of "linked lives" and that of "dynamic patterns." The notion of "linked lives" (Shanahan, 2000; Elder \& Shanahan, 2007; Pruchno, Blow \& Smyer, 1984) emphasizes that people cannot live their life independently-from others as well as from their former decisions. Life events do not occur as single, unrelated phenomena. Rather there is a path dependency (Seabrook \& Avison, 2012) in people's lives and, moreover, events are connected. People's social capital depends on the social capital of those to whom they are related as well as on their own capital in the past. While in social capital theory the "shadow of the future" (Axelrod, 1984, see above) is seen as one of the principles that guides people's actions, life course theory emphasizes the importance of a "shadow of the past." Hence, if one is equipped with only few resources, it is hard to attain more.

Another important principle within a life course perspective is that of a dynamic pattern (Elder, 1994). While many thoughts about social capital and networks are relatively static, thinking along the lines of a life course perspective about social capital implies a more dynamic, process-oriented view. Time is needed for social capital to evolve and it probably constantly changes throughout one's life-due to changes in people's opportunities, restrictions (see Feld, 1981; Fischer et al., 1977), their specific needs, and maybe also due to changes in their preferences for certain others. Furthermore, given that social capital can be understood from its function and given its goal specificity, the individual need for social capital can change during the life cycle. A young mother needs other kind of social resources than a woman who just started with a new job and moved to another city. This perspective also implies that individuals make choices, they are the architects of their life, even though their opportunities and choices are constrained (cf. Seabrook \& Avison, 2012). In this way, life course arguments parallel and complete the social capital perspective.

\subsection{Expectations}

The basic expectation here is that social capital will accumulate through people's live. It is expected that people maintain their resources as good as possible and try to avoid decline. It is not plausible that people de-invest in ties to others. Rather, people will preserve and retain their resources whenever possible. In addition, because one does not know what type and how many resources will become important in the future, people can be expected to try to enlarge their social capital whenever possible. Social capital is expected to grow through one's life, even if contact frequency declines and networks become smaller when people are aging. Note that this reasoning is in line with arguments from cumulative advantage/disadvantage theory (see Dannefer, 2003) in life course studies. Hence, it is expected that although networks become smaller, resources will be still available via the remaining members.

However, this hypothesis of social capital accumulation is probably not applicable to all social groups. As discussed above, those with a better starting position will more easily accumulate social capital through life, while for those on the lower end of the social ladder no such accumulation will be possible. Probably, people on the lower end have to invest in others in order to prevent loss of social capital, but they are not able to enlarge and accumulate their social resources. This can be seen as a Matthew effect (Merton, 1968), which will enhance and sharpen inequalities in social capital across people's life and cause a fragmentation of social capital. A favorable starting 
position can be one's education, inherited status as well as a privileged social role. For those who are in a disadvantaged opposition, the second part of the Matthew Gospel applies "Whoever does not have, even what they have will be taken from them." (Matthew, 13:12). Below, I inquire into this idea by examining social capital changes of high- and low-educated persons as well as of men and women.

Next to this conditioned accumulation of social capital, it is plausible to expect heterogeneous changes in social capital due to different types of relationships. Ties of different strength represent different forms of social capital. For example, strong ties are perfectly inclined to help, if they are able to. Weak ties are not per se willing to help, but they are in a better structural position than strong ties to do so (Granovetter, 1973). It can be expected that women, given their social role have more social capital in family networks and this might accumulate through time. For men, it can be expected that they have more weaker ties, which are allegedly more resourceful. They are expected to accumulate in particular this type of social capital. Eventually, the number of weak ties in men's social capital can be expected to decline due to retirement.

\section{The position generator instrument as a measurement of individual social capital}

There are many different ways to measure social networks, but most of them do not measure social capital. Getting to know how many friends people bears no information about valuable resources and one cannot be sure whether these friends are willing and able to help in important situations. On the contrary, given that people tend to have homogeneous networks, friends might not be able to help at all, because they have the same resources as the focal actor: similarity bears an instrumental disadvantage.

A widely established and very flexible method for measuring social capital is the namegenerating method, also called "exchange method" (Fischer, 1982). In the first step, people are asked for the network members who helped in a given situation, for example, how people got their job, their house, or to whom one talks concerning important matters. In the second step, the name interpreter, information about the person's mentioned is gathered, among which their resources and characteristics of the relationship. In addition, it can be asked to what extent network members know each other and establish some basic network structures. The method is widely used and very convenient because the exact name-generating question can be adapted to the researcher's interest and research questions. In addition, in the name interpreter step, an inquiry on social capital can be included.

Another well-established straightforward measurement is the position generator method, developed by Lin and Dumin (1986, see also Lin, Fu \& Hsung, 2001, Verhaeghe \& Li, 2015). Respondents are presented with a list of different positions or occupations and it is asked whether they know someone who has this position. If yes, respondents are also asked to indicate whether the position is hold by a friend, a family member, or a more distant acquaintance. The assumption behind this measurement is that positions in society represent resources and knowing people in specific positions implies having access to social capital. In addition, the instrument gives basic information about tie strength, the assumption is that a tie to family is stronger than a tie to an acquaintance. Hence, the instrument gives information about the size of the network, the strength of the relationship as an indicator for the willingness of the network members to help as well as their resources of these network members, indicated by the position they have. Note that the position generator gives information about access to a tie, not about actually using it (see above, section 3). The idea behind the position generator measurement is exactly this: having access to a resource makes the difference. Another important feature of the position generator instrument is that it is "content free": it does not start with existing ties and measures what kind of resources they can provide (Lin \& Erickson, 2008). Rather, it starts with the resources themselves and measures people's access. It is left open what kind of resource is provided-it assumes that a lawyer 
as well as a butcher have something important to offer. Interestingly, the instrument solves the problem of actual and hypothetical social capital sketched above just by not referring to a problem situation. It is measured whether an individual can tap into unspecified resources, not whether a specific resource is actually or hypothetically needed.

It should be kept in mind that the position generator measures a very specific part of people's social capital; it focuses on the instrumental side, more in line with rational choice arguments, but does not measure the more "expressive" side of social capital (Lin, 1999).

In summary, the position generator instrument is a straightforward measurement of microlevel social capital. It is theoretically grounded and empirically well established (Lin, Fu \& Hsung, 2001). The popularity of the instrument has grown enormously in the last years: up until now, the position generator instrument has been used in hundreds of research articles. The instrument is flexible, widely applicable, and it currently belongs to the best-established indicators of social capital.

\section{Data, measurements, and analytical strategy}

Data come from the four waves of the survey of the social networks of the Dutch (SSND). The first wave took place in 1999, the second and third in 2007 and 2014, respectively, and the fourth one in 2018. The sample is representative for the Netherlands and it is inquired into selective attrition and interviewer effects. Higher educated are slightly overrepresented, of course, the average age of the sample increased. Next to the panel, in the second and in the third wave, a refreshment sample was drawn. In 2018, only respondents that participated at least twice have been approached and no refreshment sample has been drawn. Response rate was between $40 \%$ and $60 \%$, and the overall attrition rate between 1999 and 2018 was 65\%. Numbers of respondents in the four waves are $1006,998,1067$, and 432, respectively. All interviews were conducted face to face, after careful training of the interviewers. No patterns in attrition have been found.

Most of the measurements are straightforward. With regard to the dependent variable, social capital at the four points of measurement the position generator instrument is used. The instrument (see above, section 5) allows for measuring different aspects of social capital by making a difference between the numbers of accessed positions, their average prestige, and the range of accessed prestige. Furthermore, it can be assessed how many family, friends, and acquaintances do provide this type of social capital. The number of accessed positions gives information about the extensity, the general richness of one's social capital. Average prestige is an indicator about the access to prestigious social strata, and range indicates the variety of resources. Furthermore, the different types of ties indicate tie strength. In general, it is assumed that people reach highest through weaker ties but that stronger ties are more willing to help (Granovetter, 1973, on "structure upon motivation," when it comes to people's ability to help their network members).

Consequently, the following dependent variables are constructed:

- Extensity of access to social capital. Measured by adding up all the different positions mentioned. Depending on whether only family, friends, or acquaintance are counted, the instrument measures also the differential access via these types of ties. Hence, next to total extensity, the extensity with regard to these different types of ties has also been established.

- Average prestige accessed. The occupations have been coded according to the ISCO codes for occupational prestige (Ganzeboom \& Treiman, 1996). The average accessed prestige is the sum of the prestige of all positions mentioned divided by the number of positions (extensity).

- Range of prestige accessed. The range of accessed prestige is the difference between the highest and the lowest accessed position.

In addition, it is inquired into changes of ties of different strength, that is, family, friends, and acquaintances, respectively. 
Table 1. Position generator social capital (SSND1-SSND4, $n=1006,998,1067$, and 434).

\begin{tabular}{|c|c|c|c|c|c|}
\hline Position & $\begin{array}{l}\text { SSND1 } \\
(1999)\end{array}$ & $\begin{array}{l}\text { SSND2 } \\
(2007)\end{array}$ & $\begin{array}{l}\text { SSND3 } \\
(2014)\end{array}$ & $\begin{array}{l}\text { SSND4 } \\
(2018)\end{array}$ & $\begin{array}{c}\text { (\%, difference between } \\
2018 \text { and 1999) }\end{array}$ \\
\hline Physician & 49.7 & 38.5 & 36,7 & 50.6 & 0.9 \\
\hline Cook & 46.5 & 33.4 & 35.4 & 35.8 & -10.7 \\
\hline Construction worker & 65.9 & 54.7 & 51.9 & 61.6 & -4.3 \\
\hline Director of middle-sized firm & 70.6 & 41.1 & 34.1 & 31.2 & -39.4 \\
\hline Teacher & 73.0 & 53.5 & 52.6 & 67.4 & -5.6 \\
\hline Real estate agent & 30.6 & 25.8 & 22.0 & 25.2 & -5.4 \\
\hline Union leader & 16.5 & 12.9 & 10.1 & 9.0 & -0.4 \\
\hline Lawyer & 46.6 & 37.2 & 34.3 & 44.3 & -2.3 \\
\hline Mechanic & 69.1 & 53.7 & 45.1 & 49.0 & -20.1 \\
\hline Bookkeeper & 62.8 & 54.1 & 49.9 & 52.7 & -10.1 \\
\hline Scientist & 42.1 & 37.1 & 32.6 & 43.4 & +1.3 \\
\hline Policymaker & 45.2 & 41.0 & 38.2 & 41.1 & -4.1 \\
\hline Musician & 54.2 & 45.7 & 41.7 & 50,3 & -3.9 \\
\hline Police officer & 42.0 & 35.4 & 34.8 & 36,1 & -5.9 \\
\hline Secretary & 67.1 & 57.6 & 48.9 & 54.7 & -12.4 \\
\hline Insurance officer & 40.1 & 27.1 & 22.9 & 24.7 & -15.4 \\
\hline Nurse & 75.0 & 69.1 & 59.7 & 74.2 & -0.8 \\
\hline Farmer & 50.1 & 46.2 & 38.7 & 51.9 & +1.8 \\
\hline Truck driver & 50.4 & 41.4 & 37.0 & 37.8 & -12.6 \\
\hline Postman & 27.8 & 21.0 & 20.2 & 19.3 & -8.5 \\
\hline Machinist & 18.4 & 10.5 & 6.4 & 10.3 & -8.1 \\
\hline Salesperson & 61.9 & 51.1 & 45.5 & 42.0 & $-19,9$ \\
\hline Unskilled worker & 38.0 & 70.2 & 26.4 & 27.2 & -10.8 \\
\hline Cleaning person & 34.6 & 26.2 & 28.6 & 28.4 & -6.2 \\
\hline Barber & 48.3 & 39.5 & 40.3 & 40.4 & -7.9 \\
\hline
\end{tabular}

Note that the three indicators of social capital are associated with each other in different ways. Range and extensity are correlated by definition, since every additional position mentioned adds to the final range in prestige accessed. In the data, extensity and range correlated with $\mathrm{r}=.705$. Interestingly, extensity and average accessed prestige were found unrelated, they correlate only with $r=.038$. Finally, average accessed prestige and range are weakly associated with $r=.097$.

Table 1 shows the instrument as well as the changes within the response to certain occupations within the period of 18 years. The instrument did not allow for mentioning two or more people, respondents were instructed to mention the strongest tie mentioned in case a respondent cited more than one tie (family $>$ friends $>$ acquaintances). Most occupations are mentioned with a lower rate in 2018. Partially, this could represent changes in Dutch society and economy, for example, it might hold for a Union leader, a kind of occupation that has become very rare throughout the years. However, changes in other occupations are not related to societal and economic developments, for example, numbers of cooks, barbers, or mechanics did not greatly change though the years in Dutch society but were mentioned less often. However, given that the analysis does not focus on changes in specific occupations but on changes in accessed prestige and changes 
Table 2. Description of key independent variables (overall values across the four measurements).

\begin{tabular}{lcc}
\hline & Mean $(\mathrm{sd})$ & Percentage \\
\hline Sex (female) & 49.0 \\
\hline Age at t1 & 45.1(11.16) & \\
\hline Education & \\
\hline Primary education & 7.7 \\
\hline Lower vocational training & 15.9 \\
\hline Lower secondary education & 13.3 \\
\hline Secondary education & 8.6 \\
\hline Intermediate vocational training & 19.3 \\
\hline High school & 22.2 \\
\hline University & 12.8 \\
\hline Marital status & \\
\hline Single & 11.5 \\
\hline Married/cohabitating & 70.2 \\
\hline Divorced & 10.8 \\
\hline Widowed & 7.5 \\
\hline
\end{tabular}

in network size (extensity) potential socioeconomic changes that influence the supply of specific occupations are not disturbing the results.

As to the independent variables, it is inquired into the effects of age (measured in years), sex (measured as binary variable), and education. Fixed effect models do not include control variables that are time-invariant (see below). Therefore, separate models for men and women as well as for high (people who followed a study in at least applied sciences) and lower educated (people without a diploma or with a practical education) are presented. Marital status is modeled as transition from being single to becoming married and being employed is modeled as the transition to having a job as opposed to becoming retired or unemployed. In addition, having moved is included, since one can expect that changing the place where one lives has an influence on access to social capital.

Respondents with missing variables that were crucial for the analyses (e.g., age, sex, education) were not included. Regarding the position generator instrument, we benefitted from the fact that people in general liked filling in the form, which kept the number of missing values close to zero.

Table 2 provides the descriptive statistics for the key variables in the analysis. Compared to the Dutch population, our sample is somewhat biased for higher educated and, obviously, age. And, $9.2 \%$ of the respondents were not married but cohabitating, a difference not made in the analyses.

\subsection{Statistical model}

We are interested in changes over time within persons as well as in changes between persons. For the analysis of within-person variation, fixed effect models and random effect models are most common (see Allison, 2009). Here, fixed effect models are used, after testing via the Hausmann test, which model is the best choice. Coefficients in fixed effect models represent effects of changes in the independent variables on the dependent variable. Variables that do not vary are not included in such models; only information that varies over time is used.

The data are structured as a person-wave file, where each individual is observed multiple times, depending how often s/he participated in the study. Coefficients in the model represent effects of changes in the independent variable on changes in the dependent variable. 
Table 3. Fixed effect regression on extensity, access, and range.

\begin{tabular}{|c|c|c|c|}
\hline & Extensity & Average access & Range \\
\hline Age & $.185(.056)^{\star \star \star}$ & $.087(.040)^{\star}$ & $.424(.216)^{*}$ \\
\hline Age2 & $-.002(.000)^{\star \star \star}$ & - & $-.005(.001)^{\star \star}$ \\
\hline Having moved & $-.525(.353)$ & $.139(1.05)$ & $-1.206(1.363)$ \\
\hline $\begin{array}{l}\text { Becoming/staying employed (as opposed to } \\
\text { retired and unemployed) }\end{array}$ & $1.487(.254)^{\star \star \star}$ & $.423(.750)$ & $1.271(.972)$ \\
\hline $\begin{array}{l}\text { Becoming/staying married (as opposed to wid- } \\
\text { owed/being single) }\end{array}$ & $.883(.412)^{*}$ & .806 (1.337) & $1.391(1.595)$ \\
\hline Intercept & $5.777(1.766)^{\star \star \star}$ & $45.103(2.386)^{\star \star \star}$ & $48.762(6.786)^{\star \star \star}$ \\
\hline R2 (within) & .108 & .010 & .038 \\
\hline
\end{tabular}

${ }^{\star * *} \mathrm{p}<.001 ;{ }^{* \star} \mathrm{p}<.01 ;{ }^{*} \mathrm{p}<.05 ;+\mathrm{p}<.10$

The equation for the fixed effect model is

$$
\mathrm{Y} i t=\beta 1 \mathrm{X} i t+\alpha i+\mathrm{u} i t, \text { for } \mathrm{t}=1 \ldots \mathrm{T} \text { and } \mathrm{i}=1 \ldots \mathrm{N}
$$

where

$-\alpha i(\mathrm{i}=1 \ldots \mathrm{n})$ is the unknown intercept for each respondent, the unobserved time-invariant individual effect

- Yit is the dependent variable, where $\mathrm{i}=$ respondent and $\mathrm{t}=$ time.

- Xit represents the time-variant independent variable,

$-\beta 1$ is the coefficient for the independent variable,

- uit is the error term.

As argued above, models for men, women, higher and lower educated are presented separately.

\section{Results}

\subsection{Description of social capital changes through time}

Figure 2 depicts the changes in social capital with regard to, respectively, extensity, mean prestige, and range, for ties to family, friends, and acquaintances. Concerning extensity, the number of positions that provide access to social capital has declined throughout the years. This decline can be attributed to changes in the number of friends and less so to changes in numbers of family and acquaintances positions mentioned. However, the figure also shows that the trend is not linear: the number of acquaintances rises in the last point of measurement, compared to the measurement in 2014, the third wave. Furthermore, it is interesting that for the Dutch, extensity of access to social capital via family is most prominent at all points in time. While this has been found earlier for the Netherlands (see Volker \& Flap, 2008), more access to weaker ties, such as ties to acquaintances would be more in line with the assumptions of the social capital theory. In addition, it is noteworthy that the changes in average access to social capital are quite small: although the number of those who provide access changes and declines in general, people seem to retain their levels of social capital. Range which can be seen as a measurement of the diversity of social capital or the broadness of the potential access to resources did decline, however (though also not linear), for all types of relationships. Table A1 in the appendix provides the numbers on which Figure 1 is based.

Table 3 presents the fixed effect models for all respondents, estimating effects for extensity, average access, and range. The table shows that networks of social capital positions at first grow with age, but that the curve eventually flattens. The turning point is around 45 years of age (calculated by -coefficient linear term $/ 2^{*}$ coefficient squared term). For average access, there is no 


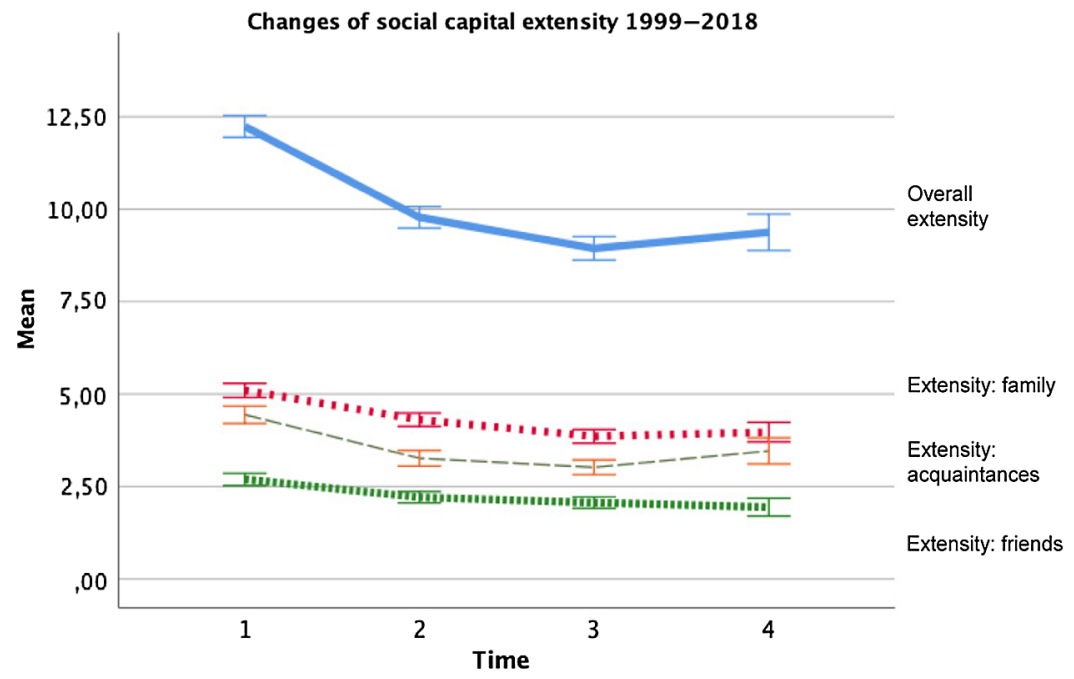

Error bars: $95 \% \mathrm{Cl}$

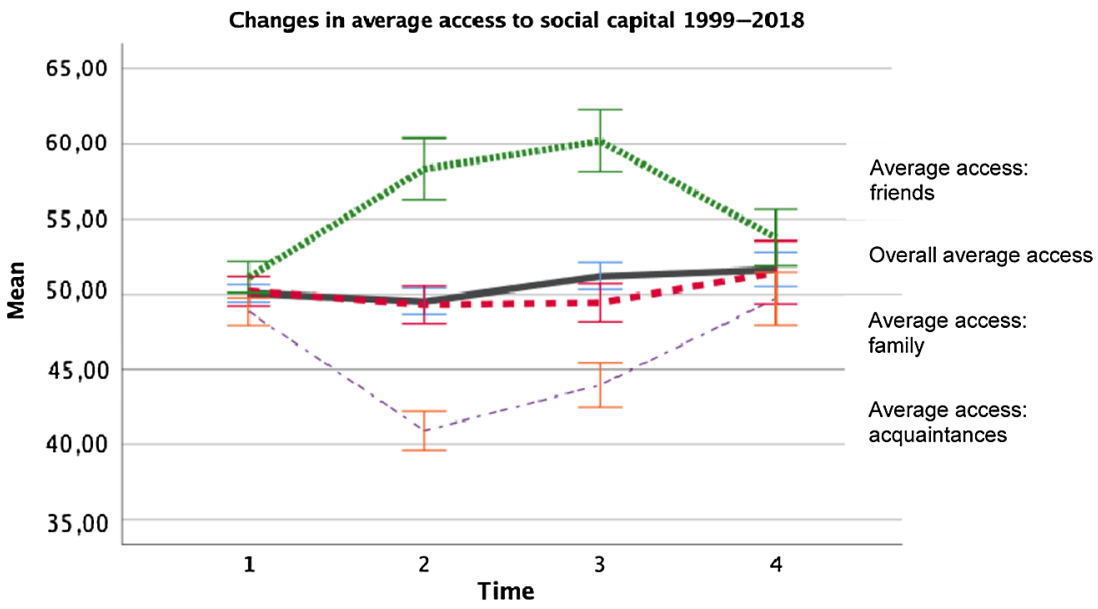

Error bars: $95 \% \mathrm{Cl}$

Changes in the range of social capital 1999-2018

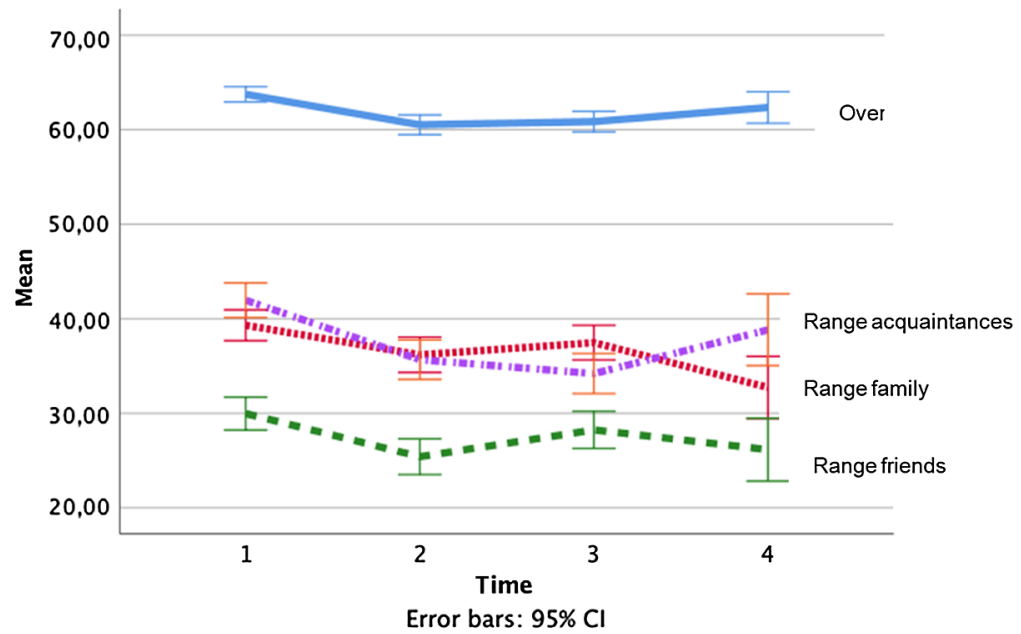

Figure 1. Changes in social capital 1999-2018. Extensity, average access, and range. 
Changes in average access to social capital for men and women (1999-2018)

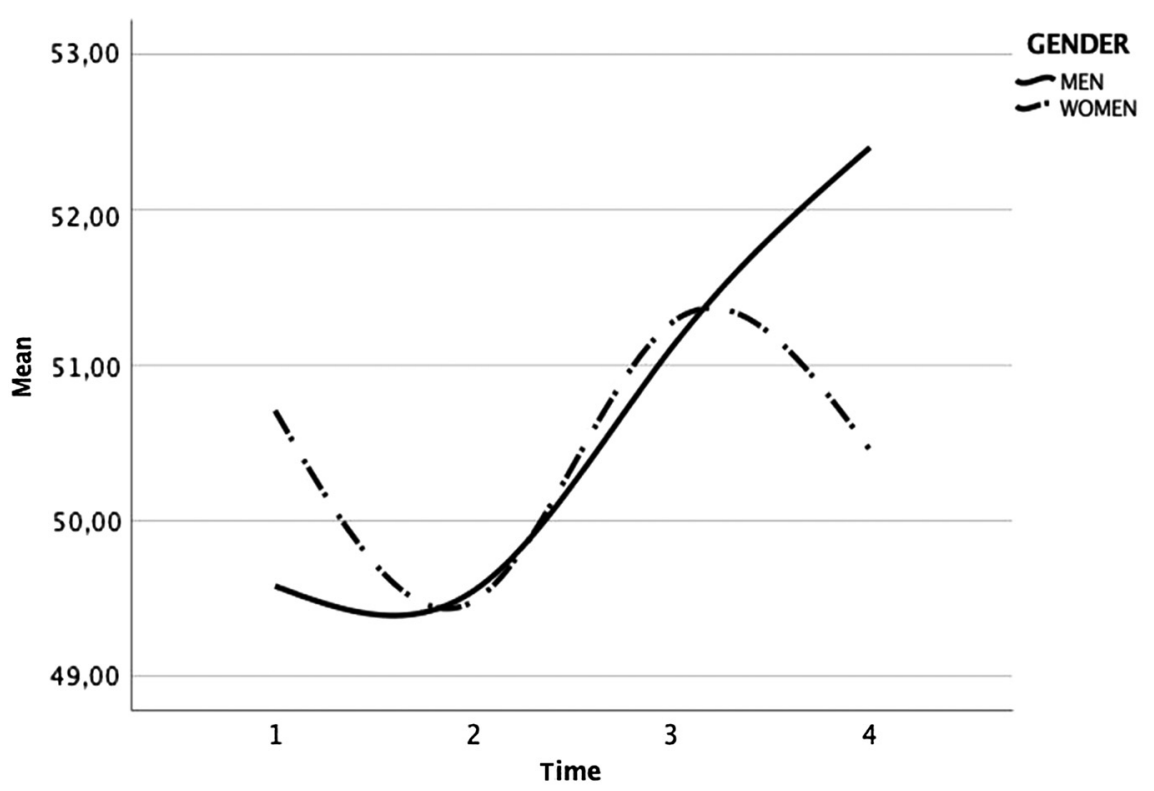

Changes in average access to social capital for high and low educated (1999-2018)

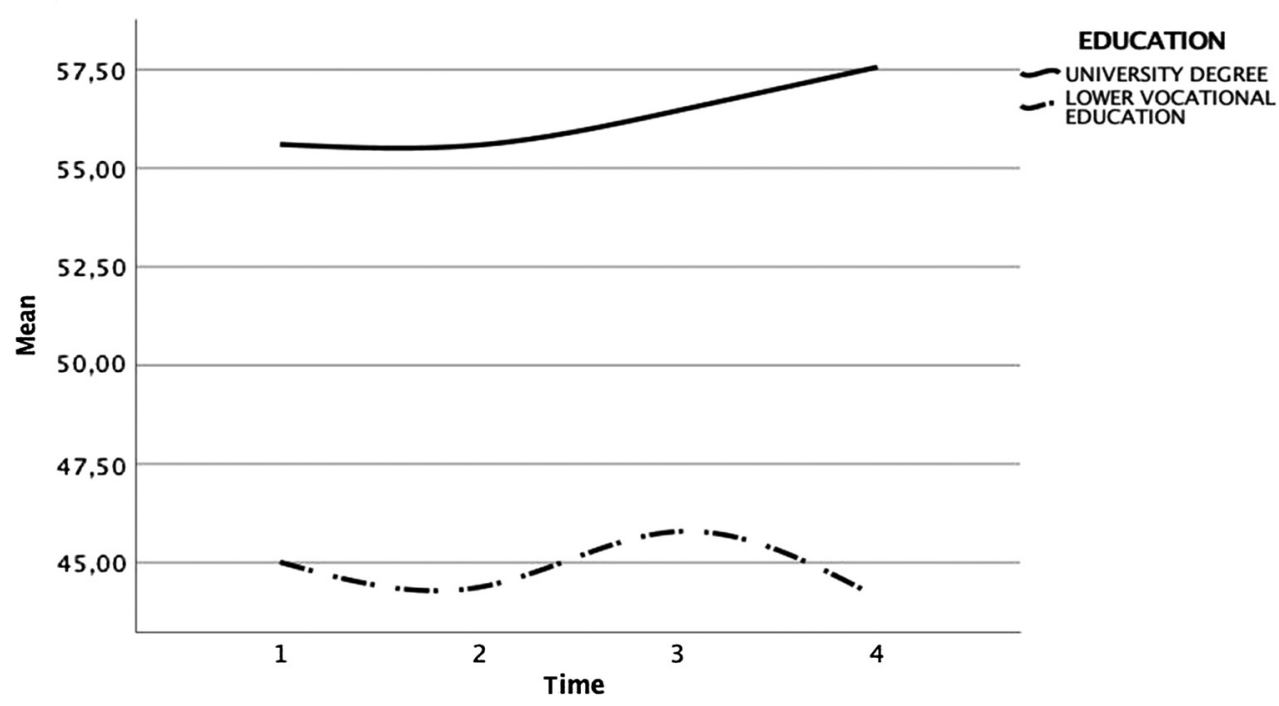

Figure 2. Changes in social capital between 1999 and 2018 for men and women and for low and highly educated.

significant quadratic term found for age, implying that there is a (small) increase through time. Finally, the change in range of accessed social capital shows the same pattern as the changes in extensity: first it increased with age, but the curve then flattens at midlife. As to life events, moving to another place has no association with changes in social capital. Becoming employed as compared to having no regular paid work enhances the number of people who provide access but is not associated with changes in average access and range. Also, marriage enhances the number of social capital positions but not its average accessed prestige and it range. 
Table 4. Fixed effect regression on extensity, access, and range for men and women.

\begin{tabular}{|c|c|c|c|}
\hline Women & Extensity & Access & Range \\
\hline Age & $.140(.088)$ & $-.006(.063)$ & $-.173(.074)^{*}$ \\
\hline Age2 & $.001(.000)^{\star}$ & - & - \\
\hline Having moved & $-.934(.557)+$ & $-.323(1.75)$ & $-1.459(2.208)$ \\
\hline $\begin{array}{l}\text { Becoming/staying employed (as opposed to } \\
\text { becoming retired and unemployed) }\end{array}$ & $1.412(.411)^{\star \star}$ & $-.189(1.160)$ & $3.264(1.557)^{\star}$ \\
\hline $\begin{array}{l}\text { Becoming/staying married (as opposed to } \\
\text { becoming widowed/being single) }\end{array}$ & $1.203(.605)^{*}$ & $.436(1.907)$ & $3.524(2.449)$ \\
\hline Intercept & $6.578(2.739)^{\star \star \star}$ & $50.629(3.762)^{\star \star \star}$ & $61.436(4.763)^{\star \star \star}$ \\
\hline R2 (within) & .102 & .004 & .043 \\
\hline Men & Extensity & Access & Range \\
\hline Age & $.222(.073)^{\star \star \star}$ & $.137(.053)^{\star}$ & $.573(.296)^{*}$ \\
\hline Age2 & $-.002(.0005)^{\star \star \star}$ & - & $-.006(.002)^{\star \star}$ \\
\hline Having moved & $-.234(.463)$ & $.248(.1 .329)$ & $-1.149(1.710)$ \\
\hline $\begin{array}{l}\text { Becoming/staying employed (as opposed to } \\
\text { becoming retired and unemployed) }\end{array}$ & $1.587(.325)^{\star \star \star}$ & $.811(.985)$ & $-.208(1.190)$ \\
\hline $\begin{array}{l}\text { Becoming/staying married (as opposed to } \\
\text { becoming widowed / being single) }\end{array}$ & $.551(.572)$ & $.519(1.876)$ & $-.404(2.11)$ \\
\hline Intercept & $5.163(2.319)^{\star}$ & $42.339(3.129)^{\star \star \star}$ & $48.060(8.52)^{\star \star \star}$ \\
\hline R2 (within) & .116 & .023 & \\
\hline
\end{tabular}

${ }^{\star \star *} \mathrm{p}<.001 ;{ }^{* *} \mathrm{p}<.01 ;{ }^{*} \mathrm{p}<.05 ;+\mathrm{p}<.10$

Table 4 presents the findings for men and women separately. Interestingly, while the turning point for the age curve is around 55 years of age for men, and after that time every additional year means a loss of network members, the linear term for age is not significant for women, only the quadratic term, which implies that there is a steady, though nonlinear decline for women. Furthermore, men gain access to average social capital when they become older, while there is no such association found for women. Last but not least, women's social capital declines in range, while men's first increases and then levels out. For both, men and women having a job implies more access to social capital in terms of extensity, but not in terms of average access to prestige positions. With regard to range of social capital, there is a decline found for women, which rises first and eventually flattens and declines around 47 years of age. Furthermore, and again for women, moving to another house is associated with decline in social capital, but not for men. Also, men but not women seem to gain social capital when they get a job. For both, getting married is associated with increase in social capital, as far as extensity is concerned, but not average access or range.

Last but not least, Table 5 summarizes the models for higher and lower educated respondents and testing the hypothesis that those who have a better starting position in terms of education will accumulate social capital while others don't. Indeed, while lower educated respondents loose social capital, when they become older, social capital of higher educated persons increases, a pattern that is found for extensity and range of social capital. Only at the age of 59 years, range of social capital declines for higher educated persons. In addition, higher educated but not lower educated gain social capital when they get a job as well as when they get married. Moving is associated with increase in the range of social capital for lower educated, but with decline for higher educated persons. 
Table 5. Fixed effect regression on extensity, access, and range for lower and higher educated.

\begin{tabular}{|c|c|c|c|}
\hline For lower educated & Extensity_ & Access & Range \\
\hline Age & $-.113(.020)^{\star \star \star}$ & $-.002(.110)$ & $-.323(.083)^{\star \star \star}$ \\
\hline Age2 & - & - & - \\
\hline Having moved & $-.359(.724)$ & $1.768(3.093)$ & $5.145(3.020)+$ \\
\hline $\begin{array}{l}\text { Becoming/staying employed (as opposed to } \\
\text { becoming retired and unemployed) }\end{array}$ & $.761(.454)+$ & $-.481(2.062)$ & $.602(1.867)$ \\
\hline $\begin{array}{l}\text { Becoming/staying married (as opposed to } \\
\text { becoming widowed / being single) }\end{array}$ & $.146(.663)$ & $-3.973(3.705)$ & $.843(2.742)$ \\
\hline Intercept & $15.10(1.420)^{\star \star \star}$ & $49.004(7.038)^{\star \star \star}$ & $68.940(5.909)^{\star \star \star}$ \\
\hline R2 (within) & .118 & .013 & .039 \\
\hline For higher educated & Extensity_ & Access & Range \\
\hline Age & $.366(.094)^{\star \star \star}$ & $.076(.054)$ & $.945(.336)^{\star \star \star}$ \\
\hline Age2 & $-.003(.001)^{\star \star \star}$ & - & $-.008(.002)^{\star \star \star}$ \\
\hline Having moved & $-.405(.530)$ & $-.205(1.425)$ & $-4.46(1.900)^{*}$ \\
\hline $\begin{array}{l}\text { Becoming/staying employed (as opposed to } \\
\text { becoming retired and unemployed) }\end{array}$ & $1.915(.398)^{\star \star \star}$ & $-.027(1.044)$ & $2.67(1.420)+$ \\
\hline $\begin{array}{l}\text { Becoming/staying married (as opposed to } \\
\text { becoming widowed / being single) }\end{array}$ & $1.487(.705)^{\star}$ & $1.181(1.774)$ & $1.60(2.58)$ \\
\hline Intercept & $2.298(2.289)$ & $48.649(3.460)^{\star \star}$ & $34.888(10.627)^{\star \star *}$ \\
\hline R2 (within) & .119 & .011 & .055 \\
\hline
\end{tabular}

${ }^{\star \star \star} \mathrm{p}<.001 ;{ }^{\star \star} \mathrm{p}<.01 ;{ }^{\star} \mathrm{p}<.05 ;+\mathrm{p}<.10$

Next to marriage, work, and moving, in preliminary analyses it was also inquired whether becoming a parent, children who leave the home or losing a household member through illness affects social capital, but these events had no stable effects on social capital.

Since my expectation that accumulation of social capital will be conditioned by the starting position of an individual, Figure 2 shows the changes in access to average prestige positions for men and women, and for lower and higher educated, respectively. It shows that-all in allwomen lose access to social capital through their lives, but men gain. Further, the gap between high and low educated has widened through time.

Next to this, a number of models (available upon request) were estimated for changes in the different types of relationships, that is, social capital provided by family, friends, and acquaintances (not presented here, available on request). With regard to extensity of social capital, it has been found that in particular access through acquaintances increases when people get a job. Furthermore, access via acquaintances decreases through moving. Concerning range of social capital provided by family members it was found that getting a job and getting married increased this range, while moving is associated with a decline of the range of social capital provided by friends. Contrary to what was expected, no evidence was found that women have more or better access to family throughout the years. Changes within different types of relationships were equal for both sexes.

\section{Conclusion and discussion}

This study employs a longitudinal perspective on social capital and made use of four measurements of social capital of a sample of respondents during a 19-year period. Fixed effect models 
estimated separately for men and women as well as for higher and lower educated respondents showed a differential pattern for these groups. The following conclusions can be drawn.

First of all, our knowledge about network changes through the life course (e.g., Kalmijn, 2012; Gillespie et al., 2015; Fischer \& Oliker, 1983) cannot straightforwardly be applied to changes in social capital. Studies on changes of networks through one's life and in different social groups consistently show that people loose friends and other network members through their life. This change is due to a shift in attention to children and partner during midlife and probably due to a later decline in social activities at higher age. While this general decline through the life course has been found for social networks, the picture for social capital is different. People maintain their social capital and while absolute numbers in accessed positions decline, access to social resources is-on average-stable.

Secondly, despite of this general pattern, there are differences in changes of social capital through time for people with different "starting positions." For men, social capital accumulates, while for women, on average, resources decline. For higher and lower educated, the pattern is even more pronounced: while the gap in access to resources between higher and lower educated is much larger than the gap between men and women, it even widens through time.

Thirdly and consequently, the differential changes between men and women and higher and lower educated enlarge social inequality and results in more segregation of social capital patterns on a societal level. It is intriguing that the range of resources increases through one's life but only for men and higher educated. Scholars, in particular Portes \& Landolt (1996), Portes (1998) and Durlauf (1999), have already argued that social capital can have undesirably consequences for social inclusion. Here, I have shown that social capital deepens social inequality and social divides. While these findings are in line with expectations resulting from social capital and life course arguments, only weak evidence has been found for particular life events, with the exception to marriage (or cohabitation) and work. Both are found to enhance social capital. Moving has comparably weak effects on changes in people's resources. In additional, analyses also having children or the "empty nest" have been examined, but they had no particular influence on social capital.

Notwithstanding that this study employed unique panel data-almost all existing studies are cross-sectional-there are a number of limitations to be mentioned. First, the sample consists almost entirely of native Dutch. In 1999, when the study started, the number of migrants in the working population was below $5 \%$, nowadays more than $20 \%$ of the Dutch population has foreign origins. Another issue that is open for discussion is that the focus of this paper has been exclusively on what is called "instrumental" social capital. We do not know how "expressive" social capital is changing over time. It is possible that changes in other types of social capital are more similar to changes of personal networks. Future research should compare changes between different forms of social capital on the one hand with changes in networks on the other hand.

Furthermore, I did not account for changes in the economy. The economic recession between 2008 and 2013 might have had an influence on positions accessed. However, my interest was not to examine changes in access to specific occupational positions, but in social capital changes, established by access to multiple positions. Still, it would be worthwhile to figure out how the supply of certain occupations in given geographical regions affects their mentioning in the social capital measurement. Also, I did not account for cohort differences (beyond age differences), due to the restricted size of the sample. Future research should establish, for example, whether the generation who witnessed the recession in the years when they entered the job market will end up with a different social capital pattern than their parents. Likewise, people who experienced an institutional breakdown at a certain age might develop social capital more cautiously and carefully than those who never saw institutions collapse.

Another new and interesting road to explore more systematically is the degree to which changes in social capital depend on each other and whether people develop compensatory strategies, for example, people might lose family social capital but invest more in resources provided by acquaintances. Last but not least, the argument about the influence of the starting position can be further 
tested by including the social position of parents. Another methodological issue is that-although I did not find any pattern in the attrition rate-it might be the case that the findings are actually biased: people who lost resources might be most likely not being traced back or refused to participate again. This would imply that the gap between those with better social positions is actually much larger.

To conclude, this paper contributes to knowledge about social capital changes through people's life and shows that while networks might decline, people by and large maintain and even enlarge their social capital. However, this does not hold for women and lower educated.

Consequently, social capital enhances rather than diminishes social divides and social inequality.

Finally, concerning the important ongoing debate about the role and the value of egocentric network research in the era of big data and network science (Perry, Pescosolido \& Borgatti, 2018), this paper shows that this type of egocentric network analyses can help to understand social structures. People's access to social positions that provide social capital is an important factor therein. The study of micro-level social capital next to the study of social networks cannot be done without egocentric network data. Big data might provide us with valuable information about meeting opportunities in certain contexts. Also, we can get very valuable information about specific types of behavior, such as online interactions, buying behavior or spatial mobility patterns. However, such data do not tell us what kind of relationships people actually develop and what type of resource they access, need, and use in the end, because they do not inform about existing relationships. Instead, they inform about the opportunities that individuals have to form relationships. Without information about actual ties, however, returns of networks-benefits of ties-cannot be understood. Further and more general, arguments about network formation cannot be tested. In other words, the mass of available data as a consequence of technical advancements provides valuable contextual or supply-side information and the opportunity structure of the setting. The other side of the coin, however, is the information about how and why people select themselves into a certain context, what type of resource or relationships they want, what tie they built up, and what the resulting benefits are in the end. This is the information about the choices people make, given their opportunities. Future work hopefully will show how both the opportunity for interaction and the actual choices can be combined.

Conflict of interest. None.

\section{Notes}

1 Because there is always a time lag between investment and returns, people need to trust each other and to belief in the norm of reciprocity. Next to investment, social capital is also created via endowment or ascription. For example, parents lend their resources to their children.

2 Probably, the discount parameter varies with the importance of the initial investment: one will never forget the person who saved one's life, but the memory on the friend who lent his bike because one's own was broken might become blurred quite soon.

\section{References}

Allison, P. D. (2009). Fixed effects regression models. Beverly Hills: Sage.

Axelrod, R. (1984). The evolution of cooperation. New York: Basic books.

Boix, C., \& Posner, D. N. (1998). Social capital: Explaining its origins and effects on government performance. British Journal of Political Science, 28(4), 686-693.

Bourdieu, P. (1981). Le capital social. Actes de la recherche en sciences sociales, 31, 2-3.

Burt, R. (1992). Structural holes: The social structure of competition. Cambridge: Harvard University Press.

Cannuscio, C., Block, J., \& Kawachi, I. (2003). Social capital and successful aging: The role of senior housing. Annals of Internal Medicine, 139(5_Part_2), 395-399. 
Chen, Y., \& Volker, B. (2016). Social capital and homophily both matter for labor market outcomes-evidence from replication and extension. Social Networks, $45,18-31$.

Coleman, J. (1990). The foundation of social theory. Boston: Belknap Press.

Coleman, J. S. (1988). Social Capital in the Creation of Human Capital, American Journal of Sociology, 94, S95-S121.

Cornwell, B., Laumann, E. O., \& Schumm, L. P. (2008). The social connectedness of older adults: A national profile. American Sociological Review, 73(2), 185-203.

Cornwell, B. (2011). Independence through social networks: Bridging potential among older women and men. Journals of Gerontology Series B: Psychological Sciences and Social Sciences, 66(6), 782-794.

Dannefer, D. (2003). Cumulative advantage/disadvantage and the life course: Cross-fertilizing age and social science theory. Journal of Gerontology, 58B, 6, S327-337.

David-Barrett, T., Kertesz, J., Rotkirch, A., Ghosh, A., Bhattacharya, K., Monsivais, D., \& Kaski, K. (2016). Communication with family and friends across the life course. PloS one, 11(11), e0165687.

De Graaf, N. D., \& Flap, H. D. (1988). With a Little Help from My Friends, Social Forces, 67, 452-472.

DiMaggio, P., \& Louch, H. (1998). Socially Embedded Consumer Transactions: For What Kinds of Purchases Do People most often Use Networks? American Sociological Review, 63, 619-637.

Durlauf, S. N. (1999). The case "against" social capital, Focus, 20(3), 1-5.

Erickson, B. H. (2004). The distribution of gendered social capital in Canada. In H. Flap, \& B. Volker (Eds.), Creation and returns of social capital (pp. 37-55). London, UK: Routledge.

Elder, G. H. (1994). Time, human agency, and social change: Perspectives on the life course. Social Psychology Quarterly, 57(1), 4-15.

Elder, G.H., Jr. and Shanahan, M.J. (2007). The life course and human development. In W. Damon, R. M. Lerner \& R. M. Lerner (Eds.), Handbook of Child Psychology. doi:10.1002/9780470147658.chpsy0112

Feld, S. L. (1981). The focused organization of social ties. American Journal of Sociology, 86(5), 1015-1035.

Flap, H., \& Boxman, E. (2001). Getting Started: The Influence of Social Capital on the Start of the Occupational Career, in N. Lin, K. S. Cook, \& R. S. Burt (Eds.), Social capital: Theory and research. New York: Aldine de Gruyter.

Flap, H., Bulder, B., \& Volker, B. (1998). Intra-organizational networks and performance: A review. Computational and Mathematical Organization Theory, 4(1998), 109-147.

Flap, H., \& Volker, B. (2004). Creation and returns of social capital. In: H. Flap, \& B. Volker (Eds.), Creation and returns of social capital (pp. 20-35). London, UK: Routledge.

Flap, H., \& Volker, B. (2013). Social Capital. Chapter 6. In R. Wittek, V. Nee, \& T. Snijders (Eds.), Handbook of rational choice social research. Palo Alto, California, US: Stanford University Press.

Fischer, C. S., Jackson, R. M., Stueve, C. A., Gerson, K., Jones, L., \& Baldassare, M. (1977). Networks and places: Social relations in the urban setting. New York: Free Press.

Fischer, C. S. (1982). To dwell among friends. Chicago: University of Chicago Press.

Fischer, C. S., \& Oliker, S. J. (1983). A research note on friendship, gender, and the life cycle. Social Forces, 62, $124-133$.

Ganzeboom, H. B. G., \& Treiman, D. J. (1996). Internationally comparable measures of occupational status for the 1988 international standard classification of occupations. Social Science Research, 25, 201-39.

Glaeser, E, Laibson D., \& Sacerdote, B. (2002). An economic approach to social capital. The Economic Journal, 112, 437-58.

Glaeser, E. (2001). The formation of social capital. Canadian Journal of Policy Research, 2(1), 34-40.

Gillespie, B. J., Lever, J., Frederick, D., \& Royce, T. (2015). Close adult friendships, gender, and the life cycle. Journal of Social and Personal Relationships, 32(6), 709-736.

Gottlieb, N. H., \& Green, L. W. (1984). Life events, social network, life-style, and health: An analysis of the 1979 National Survey of Personal Health Practices and Consequences. Health Education Quarterly, 11(1), 91-105.

Granovetter, M. S. (1973). The strength of weak ties. American Journal of Sociology, 78, 1360-80.

Hagan, J., MacMillan, R., \& Wheaton, B., (1996). New kid in town: Social capital and the life course effects of family migration on children. American Sociological Review, 61(3), 368-385.

Halpern, D. (2005). Social Capital. Polity, Cambridge, UK.

Laub, J. H. (2006). Assessing Sampson and Laub's life course theory of crime. Tacking Stock: the Status of Criminological Theory, 15, 313-333.

Leana, C. R., \& Pil, F. K. (2006). Social capital and organizational performance: Evidence from urban public schools. Organization Science, 17(3), 353-366.

Kalmijn, M. (2003). Shared friendship networks and the life course: An analysis of survey data on married and cohabiting couples. Social Networks, 25(3), 231-249.

Kalmijn, M. (2012). Longitudinal analyses of the effects of age, marriage, and parenthood on social contacts and support. Advances in Life Course Research, 17(4), 177-190.

Kawachi I. (1999). Social capital and community effects on population and individual health. Annals of the New York Academy of Sciences, 1896, 120-130.

Kawachi, I., Kennedy, B., \& Glass, R. (1999). Social capital and self-rated health: A contextual analysis. American Journal of Public Health, 89, 1187-1193. 
Lin, N., \& Dumin, M. (1986). Access to occupations through social ties. Social Networks, 8, 365-385.

Lin, N., Ensel, W., \& Vaughn, J. C. (1981). Social resources and occupational attainment. Social Forces, 59, $1163-1181$.

Lin, N. (2000). Inequality in social capital. Contemporary Sociology, 29(6), 785-795.

Lin, N. (1999). Building a network theory of social capital. Connections, 22, 28-51.

Lin, N., Fu, Y. C., \& Hsung, R. M. (2001). The position generator: Measurement techniques for investigations of social capital. In N. Lin, K. S. Cook, \& R. S. Burt (Eds.), Social capital: Theory and research (pp. 57-84). New York: Aldine de Gruyter.

Lin, N., Ao, D., \& Song, L. (2008). Production and returns of social capital: Evidence from urban China. In R.-M. Hsung, N. Lin, \& R. Breiger (Eds.), Contexts of social capital: Social networks in communities, markets and organizations (pp. 163-192). London: Routledge.

Lin, N., \& Erickson, B. (2008). Theory, measurement, and the research enterprise on social capital. In N. Lin, \& B. Erickson (Eds.), Social capital. An international research program (pp. 1-25). Oxford, UK: Oxford University Press.

McDonald, S., \& Mair, C. A. (2010). Social capital across the life course: Age and gendered patterns of network resources. Sociological Forum, 25(2), 335-359). Oxford, UK: Blackwell Publishing Ltd.

McDonald, S., Chen, F., \& Mair, C. A. (2015). Cross-national patterns of social capital accumulation: Network resources and aging in China, Taiwan, and the United States. American Behavioral Scientist, 59(8), 914-930.

Merton, R. K. (1968). The Matthew effect in science: The reward and communication system of science. Science, $199,55-63$.

Mohnen, S. M., Groenewegen, P. P., Volker, B., \& Flap, H. (2011). Neighborhood social capital and individual health. Social Science \& Medicine, 72(5), 660-667.

Moore, S., Hawe, V., \& Shiel, A. (2006). Lost in translation: A genealogy of the 'social capital concept in social health'. Journal of Epidemiology and Community Health, 60, 729-734.

Moran, P. (2005). Structural vs. relational embeddedness: Social capital and managerial performance. Strategic Management Journal, 26(12), 1129-1151.

Mouw, T. (2003). Social capital and finding a job: Do contacts matter? American Sociological Review, 68(6), 868-898.

Nordenmark, M. (1999). The concentration of unemployment families and social networks: A question of attitudes or structural factors? European Sociological Review, 15(1), 49-59.

O'Rand, A. M. (2001). Stratification and the life course: The forms of life course capital and their interrelationships.

Perry, B.; Pescosolido, B., \& Borgattti, S. (2018). Egocentric Network Analysis. Foundations Methods and Models. Cambridge University Press.

Portes, A. (1998). Social capital: Its origins and applications in modern sociology. Annual Review of Sociology, 22, 1-24.

Portes, P., \& Landolt, P. (1996) The downside of social capital. The American Prospect, 26, 18-22.

Putnam, R. (1993). Making democracy work: Civic traditions in modern Italy. Princeton, Neww Jersey, US: Princeton University Press.

Putnam, R. D. (2000). Bowling alone: The collapse and revival of American community. New York: Simon \& Schuster.

Pruchno, R. A., Blow, F. C., \& Smyer, M. A. (1984). Life events and interdependent lives. Human Development, 27(1), 31-41.

Röper, A., Volker, B., \& Flap, H. (2009). Social networks and getting a home: Do contacts matter? Social Networks, 31(1), $40-51$.

Rusbult, C. E., \& Martz, J. M. (1995). Remaining in an abusive relationship: An investment model analysis of nonvoluntary dependence. Personality and Social Psychology Bulletin, 21(6), 558-571.

Sampson, R. J., \& Laub, J. H. (1990). Crime and deviance over the life course: The salience of adult social bonds. American Sociological Review, 55(5), 609-627.

Seabrook, J., \& Avison, W. (2012). Socioeconomic status and cumulative disadvantage processes across the life course: Implications for health outcomes. Canadian Review of Sociology/Revue canadienne de sociologie, 49(1), 50-68.

Shanahan, M. J. (2000). Pathways to adulthood in changing societies: Variability and mechanisms in life course perspective. Annual Review of Sociology, 26(1), 667-692.

Schulz, R., \& Tompkins, C. A. (1990). Life events and changes in social relationships: Examples, mechanisms, and measurement. Journal of Social and Clinical Psychology, 9(1), 69-77.

Son, J. (2012). Social capital and institutional constraints: A comparative analysis of China, Taiwan and the US. London, UK: Routledge.

Song, L. (2011). Social capital and psychological distress. Journal of Health and Social Behavior, 52(4), 478-492.

Song, L. (2012). Raising network resources while raising children? Access to social capital by parenthood, gender, and marital status. Social Networks, 34, 241-252.

Song, L., \& N. Lin (2009). Social capital and health inequality: Evidence from Taiwan. Journal of Health and Social Behavior, $50,149-163$.

Thompson, J. A. (2005). Proactive personality and job performance: A social capital perspective. Journal of Applied Psychology, 90(5), 1011.

van der Gaag, M. (2004). Measurement of individual social capital. Amsterdam: Thela Thesis.

Verhaeghe, P. P., \& Li, Y. (2015). The position generator approach to social capital research: Measurements and results. In Y. Li (Ed.), Handbook of research methods and applications in social capital (pp. 166-186). Cheltenham, UK: Edward Elgar. 
Volker, B. (1995). 'Should auld acquaintances be forgot?' The institutions of communism, the transition to capitalism and personal networks. Amsterdam: Thela Thesis.

Volker, B., \& Flap, H. (2008). Reproduction of Inequality in the Netherlands through the Creation of and Returns to Social Capital? Paper presented at the International Social Capital Conference Academica Sinica, Taipei, Taiwan, May 29-30.

Volker, B., Pinkster, F., \& Flap, H. (2008). Inequality in social capital between migrants and natives in the Netherlands. Kölner Zeitschrift für Soziologie und Sozialpsychologie, 48, 325-350.

Volker, B., De Cuyper, R., Mollenhorst, G., Dirkzwager, A., van der Laan, P., \& Nieuwbeerta, P. (2016). Changes in the social networks of prisoners: A comparison of their networks before and after imprisonment. Social Networks, 47, 47-58.

Weller, S. (2010). Young people's social capital: Complex identities, dynamic networks. Ethnic and Racial Studies, 33(5), 872-888.

Wrzus, C., Hänel, M., Wagner, J., \& Neyer, F. J. (2013). Social network changes and life events across the life span: A metaanalysis. Psychological Bulletin, 139(1), 5.

\section{APPENDIX}

Table A1. Description of social capital indicators 1999-2018.

\begin{tabular}{|c|c|c|c|c|c|}
\hline & Wave 1 & Wave 2 & Wave 3 & Wave 4 & Total \\
\hline Extensity & $12.23(4.76)$ & $9.77(4.67)$ & $8.93(5.32)$ & $9.35(5.18)$ & $10.17(5.14)$ \\
\hline Family & $5.10(3.09)$ & $4.30(2.88)$ & $3.85(3.09)$ & $3.97(2.79)$ & $4.35(3.04)$ \\
\hline Friends & $2.69(2.69)$ & $2.20(2.48)$ & $2.06(2.57)$ & $1.93(2.54)$ & $2.27(2.59)$ \\
\hline Acquaintances & $4.44(3.79)$ & $3.26(3.39)$ & $3.01(3.33)$ & $3.44(3.72)$ & $3.54(3.58)$ \\
\hline Prestige & $50.05(7.37)$ & $49.51(9.97)$ & $51.19(9.78)$ & $51.61(7.96)$ & $55.96(17.32)$ \\
\hline Family & $49.35(11.95)$ & $48.27(13.47)$ & $47.53(13.77)$ & $49.40(14.24)$ & $48.52(13.24)$ \\
\hline Friends & $51.09(13.33)$ & $56.68(21.93)$ & $58.02(21.72)$ & $52.23(14.52)$ & $54.83(18.98)$ \\
\hline Acquaintances & $48.70(11.76)$ & $40.87(14.73)$ & $42.88(16.03)$ & $49.57(12.67)$ & $45.02(14.43)$ \\
\hline Range & $60.72(13.28)$ & $55.04(16.67)$ & $52.88(19.95)$ & $54.23(18.15)$ & $55.96(17.32)$ \\
\hline Family & $41.40(20.26)$ & $37.85(21.48)$ & $36.26(22.64)$ & $35.58(21.99)$ & $38.18(21.64)$ \\
\hline Friends & $29.44(22.65)$ & $26.11(22.55)$ & $27.32(23.88)$ & $24.56(22.97)$ & $27.32(23.08)$ \\
\hline Acquaintances & $41.23(23.69)$ & $34.07(24.56)$ & $32.23(25.96)$ & $35.53(26.73)$ & $36.01(25.23)$ \\
\hline
\end{tabular}

Cite this article: Volker B. (2020). Social capital across the life course: Accumulation, diminution, or segregation? Network Science 8, 313-332. https://doi.org/10.1017/nws.2020.26 